\title{
CONTABILIDADE DECISORIAL: UM SISTEMA INTEGRADO DE INFORMAÇÕES PARA DIRETORES E GERENTES
}

\section{JOSÉ LUIZ B. PARANHOS}

Sumário: 1. O que é contabilidade decisorial. 2. $O$ custo direto. 3. Contribuição marginal ou margem de contribuição. 4. Tratamento dispensado às despesas regulares e programados. 5. Contribuição das linhas. 6. Aplicação de standards. 7. Apresentação do resultado econômico. 8. Demonstração da situação patrimonial. 9. Segurança nas informaçöes. 10. Informações para estudos especiais. 11 . Simplicidade na operação. 12. Principais vantagens. 13. Planejamento geral e previsão do lucro. 14. Versátilidade - cuidados na implantação.

Nos contatos diários com homens de emprêsa e responsáveis pela administração de negócios, sente-se uma preocupação sempre crescente com o aperfeiçoamento de métodos e sistemas administrativos visando a prover as emprêsas de informações mais precisas, objetivas e rápidas, de modo a atenderem melhor suas necessidades em face da conjuntura econômica em evolução.

De fato, diversas técnicas administrativas, que há dez anos preenchiam plenamente sua finalidade, hoje já estão se tornando obsoletas e vêm sendo substituídas por outras mais avançadas e adequadas às necessidades atuais.

José LuIz B. PaRANHos - Engenheiro, consultor em Administração de Emprêsas, Assistente da Diretoria encarregado dos programas de desenvolvimento técnico da OECI - Organizadores, Economistas e Consultores Industriais Ltda., São Paulo.

R. Adm. Emp., Rio de Janeiro, 9 (1): p. 72-92, jan.-mar. 1969 
Grande interêsse vem despertando, nos meios empresariais, um sistema bastante completo de informações de natureza econômico-financeira, que está sendo aplicado no Brasil há quase cinco anos com excelentes resultados. Trata-se da Contabilidade Decisorial sôbre a qual tentaremos dar uma idéia rápida ao leitor, mencionando os principais proveitos que se podem tirar de suas características.

O sistema em pauta foi baseado em um que vem sendo largamente empregado nos Estados Unidos da América Profitability Accounting ${ }^{\perp}$ - e que, pelas suas excelentes qualidades, tem sido um dos elementos decisivos no sucesso de grandes organizações, como no caso da Chrysler, por exemplo.

Não se trata de uma simples tradução do Profitability Accouting, mas sim de uma adaptação dos conceitos e métodos daquele sistema à nossa realidade econômica e ao grau de desenvolvimento de nossas emprêsas, adaptação esta já testada na prática em várias organizações, não só industriais, mas, também, no ramo bancário. Criamos, portanto, uma designação nacional, Contabilidade Decisorial, procurando mostrar sua grande utilidade como elemento de apoio aos dirigentes empresariais, na tomada de decisões.

Dada sua grande versatilidade, a Contabilidade Decisorial é aplicável, pràticamente, a todo tipo de emprêsa, identificando-se, perfeitamente, com suas características.

Êste fato vem dificultar uma explanação técnica perfeita do assunto. Por conseguinte, trataremos a matéria expondo os conceitos básicos do sistema, imaginando, para os exemplos citados, uma emprêsa média, com linhas regulares de produtos e onde o faturamento mensal possa servir de base para as demonstrações do resultado. Convém ressaltar que esta escolha tem caráter puramente didático e que a Contabilidade Decisorial pode ser aplicada indistinta-

1 BAYER, RoBert. Profitability Accounting for Planning and Control, Nova Iorque, The Ronald Press Compary, 1963. 
mente a qualquer tipo de emprêsa, quer tenha ou não linhas regulares, quer possa ou não contar com um faturamento mensal para apuração do resultado.

1. O QUE É A CONTABILIDADE DECISORIAL

A Contabilidade Decisorial é um sistema integrado de informações que visa a oferecer aos administradores através de uma coerência conseguida entre as diversas fontes de dados da emprêsa - os elementos mais adequados para servirem de apoio às suas decisões.

Dotado de grande objetividade e presteza na apresentação das informações, o sistema compele o administrador a decidir - e decidir bem - sôbre as medidas a serem tomadas para corrigir os pontos fracos ou estimular os efeitos favoráveis. Daí a designação de Contabilidade Decisorial dada ao sistema, denominação que passaremos a escrever, abreviadamente, $\mathrm{CD}$.

Aproveitando as técnicas e conceitos de:

- custo direto e contribuição marginal

- custos padrões

- distribuição de despesas

- contrôle orçamentário

- planejamento do lucro

- análise da rotação e rentabilidade de capital

- análise de situação patrimonial

- elementos modulados (building blocks)

a CD oferece, com a segurança própria dos sistemas contábeis :

- demonstração do resultado econômico, dando destaque às variações em relação aos standards e aos planos prèviamente estabelecidos;

- análise econômica do desempenho comercial;

- análise da lucratividade de produtos, linhas e filiais;

- elementos para o estabelecimento de política de preços em bases mais competitivas;

- dados sôbre o retôrno e lucratividade do capital; 
- elementos para análise econômico-financeira dos investimentos;

- dados para decidir entre comprar ou fabricar;

- informações de detalhes aos escalões inferiores da administração da emprêsa;

- e outras informações de cada emprêsa.

Tôdas as técnicas e conceitos empregados e mais outros correlatos são, isoladamente, bastante conhecidos e, uns ou outros, já eram, com maior ou menor freqüência, praticados antes que ROBERT BAYER escrevesse seu livro, embora não da forma completa, harmônica e eficiente por êle realizada. A Profitability Accounting - ou a CD faz $\mathrm{o}$ aprimoramento dêles e estabelece sua integração num sistema unificado de informações, garantindo, desta forma, perfeita coerência nos elementos apresentados e evitando distorções por vícios de preparação ou interpretação dos dados.

Dado o seu grau bastante avançado, a CD tem sido introduzida nas emprêsas por etapas, destacando-se dois estágios:

$1 .^{\circ} \quad$ onde se estabelecem os contrôles dentro das técnicas e conceitos da CD;

2..$^{\circ}$ onde se implantam as técnicas de planejamento de lucro, contrôle orçamentário e conseqüente previsão da evolução da situação patrimonial, etapas estas que dependem, para seu bom funcionamento, dos dados obtidos através dos contrôles introduzidos no $1 .^{\circ}$ estágio.

Neste artigo falaremos mais dos conceitos empregados no primeiro estágio que, como se poderá ver, já representam um avanço apreciável das técnicas de administração. Num próximo trabalho, comentaremos as características do segundo estágio.

2. o CUSTO DIRETO

A Contabilidade Decisorial utiliza para o custeio dos produtos os conceitos do custo direto - preferimos a designação de custo incremental. Assim, o custo dos produtos 
é calculado sòmente com as despesas proporcionais ao volume de produção - e vendas - isto é, despesas variáveis, sendo as demais denominadas fixas, lançadas diretamente contra o resultado. Estas últimas a $\mathrm{CD}$ classifica em regulares e programadas, do que falaremos mais: adiante.

A aplicação do custo direto faz com que os custos dos produtos não dependam do volume de produção e vendas, e permite conhecer, com melhor precisão, a influência dêste volume no resultado da emprêsa. Simplifica, também, os trabalhos de cálculo, pois os elementos que o compõem são em número reduzido.

3. CONTRIBUIÇÃo MARGINAL OU MARGEM DE CONTRIBUIÇÃo ${ }^{2}$

$O$ conceito da contribuição marginal, ${ }^{3}$ decorrente do custo direto, é largamente empregado, e com grande ênfase, pela CD.

A contribuição marginal é a diferença entre o valor das vendas e as despesas proporcionais correspondentes, ou seja, o valor das vendas menos o custo direto - incremental - dos produtos vendidos. Ela representa o que sobra das vendas para absorção das despesas regulares e programadas (fixas) e formação do lucro. Dada sua definição, êste conceito é aplicável tanto para o total da emprêsa como para uma unidade de produto, uma linha, ou uma filial isoladamente.

A contribuição marginal global é proporcional ao volume de vendas e quanto maior fôr o seu montante maior será o lucro auferido. Para se conhecer o lucro basta deduzir, da contribuição marginal, as despesas regulares e as programadas.

Por outro lado, quando associada a uma unidade de produto, a contribuição marginal - unitária - reflete o

2 DiAs, Ivan Pinto. Algumas Observações sôbre a Margem de Contribuição, Revista de Administração de Emprêsas, Rio de Janeiro: Fundação Getúlio Vargas, vol. 7, n. ${ }^{\circ} 24$, setembro de 1967.

3 Em inglês encontram-se várias designaçōes para a Contribuição Marginal, das quais citamos: Marginal Income, Profit Contribution, Contribution Margin, Marginal Contribution, Variable Income, Contribution to Fixed Costs and Income, etc. 
quanto rende a venda desta unidade, qualquer que seja o volume de produção e/ou vendas. Torna-se, portanto, um elemento de alto significado no conhecimento comparativo da rentabilidade dos produtos, ou nas decisões sôbre qual produto deverá ter suas vendas incrementadas.

A contribuição marginal é medida não só em cruzeiros, mas, também, em porcentagem, em relação às vendas ou preço de vendas no caso de um produto. Esta porcentagem indica, de um modo analógico, a velocidade com que aumentam os lucros com a elevação do volume de vendas. É, portanto, aplicável para se medir a rentabilidade da emprêsa, de produtos, de linhas, etc.

A utilização dêsse conceito faz com que as decisões sejam tomadas tendo por base o que rende cada produto ou uma linha - o que é mais objetivo - e não tanto com fundamento no que custam êsses artigos.

O Gráfico 1 ilustra o conceito aqui emitido.

GRÁFICO 1

Ponto de Equilíbrio

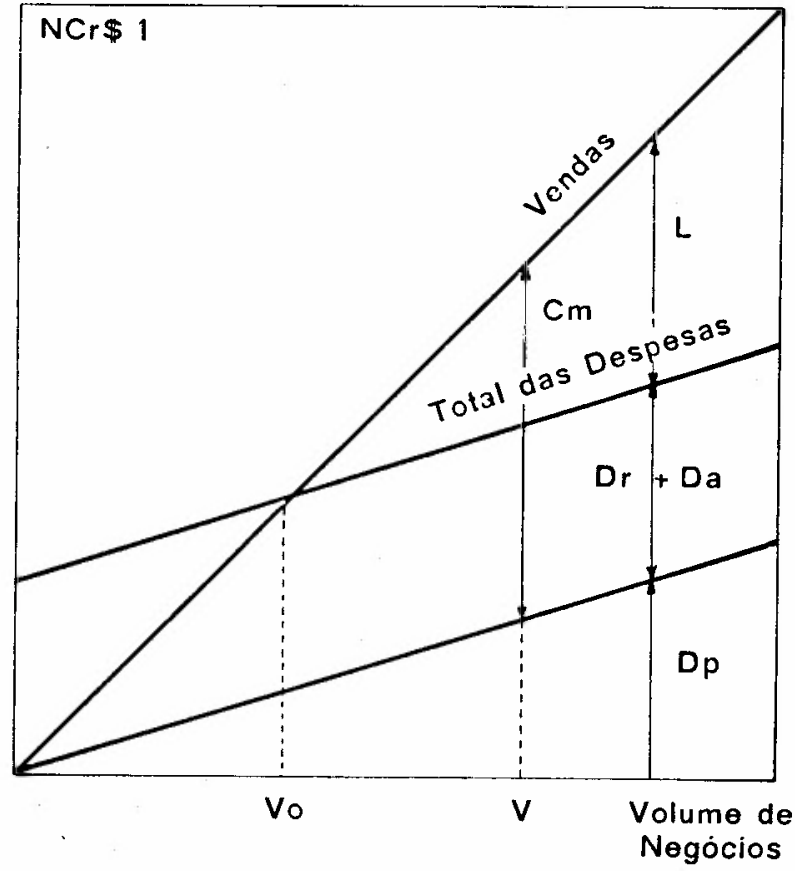




$$
\begin{aligned}
& \mathrm{Dp}=\text { despesas proporcionais } \\
& \mathrm{Dr}=\text { despesas regulares } \\
& \mathrm{Da}=\text { despesas programadas } \\
& \mathrm{Dr}+\mathrm{Da}=\text { despesas fixas } \\
& \mathrm{Cm}=\text { contribuição marginal } \\
& \mathbf{L}=\text { lucro } \\
& \mathbf{V}=\text { valor das vendas } \\
& \text { Vo }=\text { ponto de equilíbrio } \\
& \text { (valor das vendas para } \\
& \text { não se terem lucro nem } \\
& \text { prejuízo). } \\
& \mathbf{v}-\mathbf{D p}=\mathbf{C m}=\mathrm{Dr}+\mathrm{Da}+\mathbf{L} \\
& \frac{\mathrm{L}}{\mathrm{V}}=\frac{\mathrm{Cm}}{\mathrm{V}}-\frac{\mathrm{Dr}+\mathrm{Da}}{\mathrm{V}} \\
& \mathrm{Vo}=\frac{\mathrm{Dr}+\mathrm{Da}}{\mathrm{Cm} / \mathrm{V}}
\end{aligned}
$$

Em abscissas, está representado o volume de negócios, na unidade mais adequada à emprêsa - NCr\$, toneladas, $\mathrm{m}^{3}$, peças, etc. - e, em ordenadas, o valor em $\mathrm{NCr} \$$ das grandezas que estão sendo relacionadas com aquêle volume de negócios.

A primeira reta inclinada - de baixo para cima - representa as despesas proporcionais (Dp) que crescem com 0 aumento dos negócios. A segunda reta inclinada representa o total das despesas e é construída paralelamente à primeira. A distância entre ambas, constante para qualquer volume de negócios, representa as despesas fixas $(\mathrm{Dr}+\mathrm{Da})$. Por fim, a terceira reta inclinada representa o valor das vendas. No ponto onde esta reta encontra a segunda, isto é, onde o valor das vendas se iguala ao das despesas, não se tem lucro nem prejuízo. E o ponto de equilíbrio também chamado ponto de paridade, ponto de ruptura (break even point).

Para um volume de negócios superior a êsse ponto (Vo) a emprêsa tem lucro; a reta das vendas está acima da do total das despesas. Quando as vendas são inferiores, aparece um prejuízo, ficando a reta das vendas abaixo da reta do total das despesas. 
A contribuição marginal (CM) é representada pelas distância entre a reta das vendas e a reta das despesas proporcionais.

Pode-se ver, claramente, que, para um acréscimo do volume de negócios se tem um aumento em NCr\$ da contribuição marginal exatamente igual ao aumento do lucro.

\subsection{Observação}

O gráfico em questão constitui, como é óbvio, um modêlo. bastante simplificado do que acontece na realidade, mas bastante útil para a compreensão dos conceitos emitidos. Modelos mais sofisticados têm sido desenvolvidos, por diversas autores, para atenderem principalmente, objetivos de planejamento do lucro e contrôle orçamentário. Por exemplo: GlenN A. Welsch, ${ }^{4}$ J. Brooks Heckert 2 JAMes D. Wilson ${ }^{5}$ Robert Bayer, ${ }^{6}$ IVAN Pinto Dias ${ }^{7}$.

4. TRATAMENTO DISPENSADO ÀS DESPESAS REGULARES E PROGRAMADAS

As despesas "fixas" são classificadas pela $\mathrm{CD}$ em regulares e programadas. As primeiras são de natureza corrente e absolutamente necessárias ao bom funcionamento da emprêsa, sendo, portanto, pràticamente, irrecorríveis. As medidas de contenção não podem ser aplicadas a curto prazo, necessitando modificações relativamente profundas na estrutura da emprêsa ou de seus métodos de trabalho por exemplo, a mecanização da escrituração contábil.

As segundas são de decisão da alta administração e uma contenção imediata não traz solução de continuidade aos. trabalhos da emprêsa. Constituem bons exemplos os gastos de propaganda, pesquisa de mercado, estudo de novos produtos, gratificações extras a funcionários.

4 Welsch, Glenn A. Budgeting, Profit Planning and Control, Englewood Cliffs, Nova Jersey, Prentice-Hall, Inc., 2nd Edition, p. 325 em diante.

5 Heckert, J. Brooks C. P. A., e Wilson, James D.C.P.A. Business Budgeting and Control, Nova Iorque, The Ronald Press, Company, 2nd Edition, p. 359 em diante.

- Bayer, Robert. op. cit., p. 136.

7 DiAs, Ivan Pinto. Algumas Observações sôbre a Margem de Contribuição, Revista de Administração de Emprêsas, Rio de Janeiro, Fundação Getúlio Vargas, vol. 7, n. ${ }^{\circ} 24$, setembro de 1967. 
As despesas fixas - regulares e programadas - são incorporadas ao resultado por totais, dispensando-se, para êste fim, os rateios trabalhosos sempre presentes num sistema de custos por absorção. Por outro lado, elas são analisadas por natureza, por linha e por responsabilidade, sem que desta análise dependa a demonstração global do resultado, favorecendo, dêste modo, a rapidez desta apresentação sem prejuízo para os detalhes.

Numa análise por linha, é dada atenção sòmente às despesas próprias de cada uma, então designadas despesas específicas. Em outras palavras, a cada linha são associadas as despesas conhecidas como próprias de cada uma. As demais, comuns a tôdas, permanecem num único grupo - despesas de conjunto - e assim são incluídas nas demonstrações. Mais uma vez, ganham-se tempo e objetividade nas demonstrações, eliminando-se tôda a sorte de rateios trabalhosos e subjetivos empregados nos sistemas tradicionais de custo.

$\mathrm{Na}$ análise por responsabilidade procura-se atribuir a responsabilidade dos gastos às pessoas que efetivamente os realizam ou sôbre êles decidem. Neste sentido, é de suma importância que a emprêsa tenha o organograma e as funções de cada setor perfeitamente definidos. Ao estudar as seções que compõem um mesmo departamento, verifica-se que alguns gastos - como, por exemplo, salários e ordenados do pessoal, materiais de consumo - podem ser corretamente apropriados a cada uma. Outros são de caráter geral do departamento e não se tem um critério justo para associá-los às seções; por exemplo, gastos com os auxiliares diretos do chefe do departamento - assistente, secretária - com os materiais por êles consumidos, etc.

A CD, em suas análises, apresenta as despesas da emprêsa associadas a cada setor, levando-se em conta o nível hierárquico em que são efetuadas. Assim, enquanto as seções recebem os gastos do seu pessoal próprio, do seu consumo de material, o chefe do departamento é responsabilizado pelas despesas comuns às seções; o chefe da divisão, pelas 
despesas genéricas dos respectivos departamentos; e a própria diretoria, por aquêles gastos relativos à emprêsa tôda, como alguns impostos, seguros, estudos especiais, etc.

São evitadas, quanto possível, tôdas as espécies de rateios - cujos critérios são quase sempre discutíveis - que, para atenderem a finalidades puramente contábeis, freqüentemente prejudicam os objetivos de contrôle administrativo. A CD, através dos conceitos de contabilidade por responsabilidade, que acabamos de expor resumidamente, dá maior ênfase a êsse tipo de informação rápida e objetiva, deixando num segundo plano - mas dêles não descuidando - os problemas de classificação contábil.

5. CONTRIBUIÇÃo DAS LINHAS

Com a análise das despesas por linha pode-se determinar a contribuição da linha - deduzindo-se da contribuição marginal as respectivas despesas específicas - que corresponde ao montante com que cada linha contribui para absorver as despesas de conjunto e formar o lucro.

Com êsse nôvo conceito, aplicável também ao caso de filiais, pode-se conhecer, com boa exatidão, a rentabilidade das linhas, auxiliando a administração no estudo dos problemas correlatos.

\section{APLICAÇÃO DE STANDARDS}

A Contabilidade Decisorial prevê, ainda, a utilização de standards - atualmente possível e favorecida pela política antiinflacionária do govêrno - que, aplicados ao valor das vendas, ao custo incremental, ao preço das matériasprimas, à contribuição marginal e a outros valôres básicos, trazem novas e apreciáveis vantagens ao sistema.

Os desvios ocorridos são destacados nas demonstrações e, dêste modo, chamam a atenção para os pontos críticos que requerem tomada imediata de medidas saneadoras.

Tem-se, também, a comparação de dados de um mês para outro, ou entre uma linha e outra, elaborados em bases homogêneas. Assim, por exemplo, o valor que representa 
o volume das vendas não é afetado por uma política promocional de descontos nos preços e pode ser comparado com outros meses em que esta política seja diferente.

Os dados de estoque também não são influenciados pelas oscilações de preço e custo, o que sempre ocorre de um mês para outro. Todavia, a realidade dos fatos não é adulterada, uma vez que se demonstram, em separado, os desvios ocorridos.

\section{APRESENTAÇÃO DO RESULTADO ECONÔMICO}

A CD prevê também o método para a elaboração dos relatórios para administração, assim como a forma de sua apresentação. Apresentamos a demonstração do resultado em dois esquemas simples (vide Esquemas 1 e 2 ).

O primeiro traz apenas o resultado global. Parte-se das vendas - produtos entregues, valorizados dos respectivos preços de tabela - deduzindo-se, sucessivamente, os valôres-padrão das despesas proporcionais de vendas e do custo incremental de fabricação, obtendo-se, como primeiro subtotal, a contribuição marginal padrão conseguida. Em seguida, deduzem-se as despesas regulares e programadas, obtendo-se um primeiro resultado, dito padrão, que é, então, corrigido pelas variações constatadas entre os gastos reais e os respectivos padrões. Ao resultado corrigido - decorrente das operações regulares da emprêsa - são somados receitas e gastos eventuais, e deduzida uma provisão para o Impôsto de Renda, formando, assim o resultado líquido.

O segundo esquema, semelhante ao primeiro, introduz a análise do resultado por linha e/ou filial. Os elementos que entram na formação da contribuição marginal standard são perfeitamente identificáveis com as linhas e/ou filiais. As despesas regulares e programadas têm parcelas perfeitamente identificáveis com determinadas linhas e/ou filiais - e que são denominadas despesas específicas e outras, comuns a tôdas. As primeiras aparecem distribuídas nas respectivas linhas e/ou filiais, ao passo que as de 
ESQUEMA 1: Apresentação das Informações Mensais RESULTADO GLOBAL

\begin{tabular}{|c|c|}
\hline FATURAMENTO & 310 \\
\hline $\begin{array}{l}\text { VENDA (Preço de Tabela) } \\
\text { Menos Custo Incremental Vendas (STD) } \\
\text { Menos Custo Incremental Fabric. (STD) } \\
\text { CONTRIBUIÇÃO MARGINAL (STD) } \\
\text { Menos Despesas Regulares } \\
\text { Menos Despesas Programadas } \\
\text { RESULTADO (STD) }\end{array}$ & $\begin{array}{r}325 \\
-\quad 40 \\
-115 \\
=170 \\
=\quad 110 \\
=\quad 10 \\
=\quad 50 \\
\end{array}$ \\
\hline $\begin{array}{l}\text { VARIAÇÕES } \\
\text { Var. Preço } \\
\text { Var. Custo Incremental Venda } \\
\text { Var. Custo Incremental Fabric. } \\
\text { TOTAL DAS VARIAÇÕES }\end{array}$ & $\begin{array}{r}(15 \\
3 \\
9 \\
(3 \\
\end{array}$ \\
\hline $\begin{array}{l}\text { RESULTADO CORRIGIDO } \\
\text { OUTRAS RENDAS }\end{array}$ & $\begin{array}{r}=47 \\
+\quad 5 \\
\end{array}$ \\
\hline $\begin{array}{l}\text { RESULTADO TOTAL } \\
\text { Menos Impôsto de Renda }\end{array}$ & $\begin{array}{l}=52 \\
-\quad 14 \\
\end{array}$ \\
\hline $\begin{array}{l}\text { RESULTADO LÍQUIDO } \\
\text { ( ) Variações desfavoráveis }\end{array}$ & $=38$ \\
\hline
\end{tabular}

ordem geral figuram apenas nos totais, como despesas de conjunto. $O$ mesmo ocorre com as variações, o que pode ser melhor visto no exemplo do Esquema 3.

Pode-se observar o destaque dado aos elementos mais significativos que compõem o resultado econômico e a facilidade com que se podem localizar os pontos desfavoráveis. Observemos, por exemplo, a última linha da demonstração: nas colunas Venda, Custo Incremental e Contribuição Marginal (STD), apareceram os respectivos elementos padrões somente influenciados pelo volume de vendas atingido e pela proporção com que cada produto entra na composição dêsse volume.

A contribuição marginal STD é aquela que seria obtida se tôdas as vendas fôssem feitas a preço de tabela e os produtos respectivos tivessem seu custo exatamente dentro dos padrões previstos. 
ESQUEMA 2: Apresentação das Informações Mensais Analisadas por Linhas e/ou Filiais

\begin{tabular}{|c|c|c|c|c|}
\hline \multirow{2}{*}{ RESULTADO DAS LINHAS/FILIAIS } & \multirow{2}{*}{ TOTAL } & \multicolumn{3}{|c|}{ Linha/Filial } \\
\hline & & $\mathbf{A}$ & $\mathrm{B}$ & $\mathbf{C}$ \\
\hline FATURAMENTO ........ & 310 & 120 & 110 & 80 \\
\hline $\begin{array}{l}\text { VENDA (Preço de Tabela)................. } \\
\text { Menos Custo Incremental Vendas (STD).... } \\
\text { Menos Custo Incremental Fabric. (STD).... } \\
\text { CONTRIBUIÇÃO MARGINAL (STD) ... } \\
\text { Menos Desp. Regulares Específicas.......... } \\
\text { Menos Desp. Program. Específicas.......... }\end{array}$ & $\begin{array}{r}325 \\
-\quad 40 \\
-\quad 115 \\
=\quad 170 \\
-\quad 60 \\
-\quad 6 \\
\end{array}$ & $\begin{array}{r}125 \\
16 \\
45 \\
64 \\
24 \\
2\end{array}$ & $\begin{array}{r}115 \\
14 \\
40 \\
61 \\
21 \\
2\end{array}$ & $\begin{array}{r}85 \\
10 \\
30 \\
45 \\
15 \\
2\end{array}$ \\
\hline CONTRIBUIÇÃO DA LINHA/FILIAL... & $=104$ & 38 & 38 & 28 \\
\hline 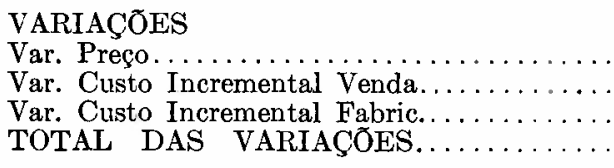 & $\begin{array}{c}(15) \\
3 \\
9 \\
(3)\end{array}$ & $\begin{array}{c}(5) \\
1 \\
4 \\
(0)\end{array}$ & $\begin{array}{c}(5) \\
1 \\
3 \\
(1)\end{array}$ & $\begin{array}{r}(5 \\
1 \\
2 \\
(2\end{array}$ \\
\hline $\begin{array}{l}\text { CONTRIBUIÇÃO CORRIGIDA.. } \\
\text { Menos Desp. Regul. de Conjunto. }\end{array}$ & $\begin{array}{r}=101 \\
-\quad 50\end{array}$ & 38 & 37 & 26 \\
\hline $\begin{array}{l}\text { Menos Desp. Program. de Conjunto........ } \\
\text { RESULTADO CORRIGIDO .............. }\end{array}$ & $\begin{array}{l}-\quad 4 \\
=\quad 47\end{array}$ & & & \\
\hline
\end{tabular}

As despesas regulares e programadas são tiradas — neste primeiro estágio - da Contabilidade Geral e, após os ajustes normais, vão figurar nas colunas correspondentes da demonstração. A comparação fácil com períodos anteriores indica se a emprêsa está se mantendo dentro de uma tendência normal de gastos fixos.

Em seguida, vem o resultado standard - diferença entre a contribuição marginal STD e as despesas regulares e programadas - resultado êste que precisa ser ajustado para se ter o resultado correto da emprêsa. Esste ajuste é feito pelo montante das variações decorrentes das anormalidades de desempenho, e que, pela forma como estão classificadas, já indicam o setor responsável.

A variação de preço mostra a diferença entre as vendas calculadas a preço de tabela e o faturamento real do período, indicando o que custa à emprêsa o montante dos descontos concedidos aos clientes - previstos ou não. As 

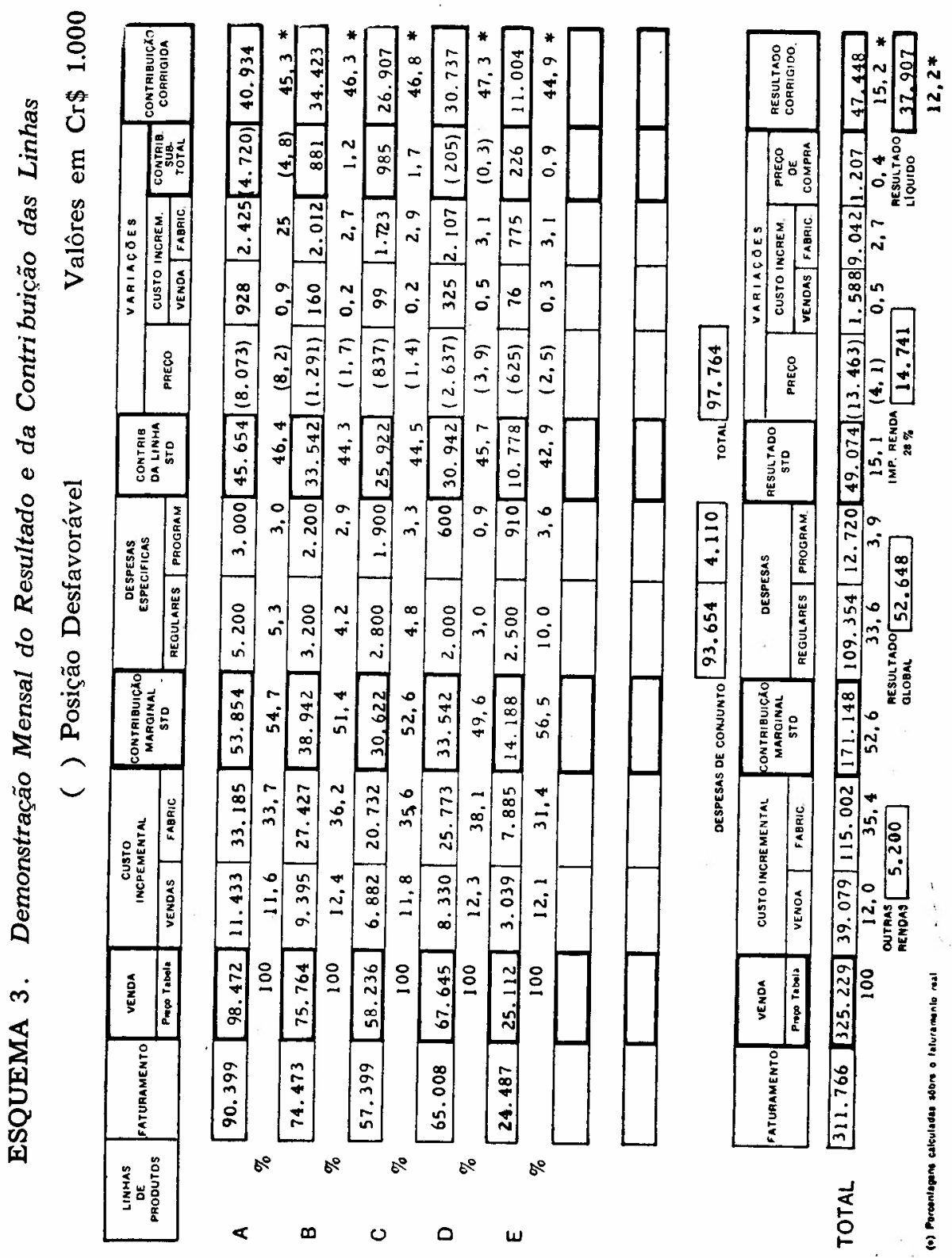
anormalidades são discutidas com o responsável pelo setor comercial.

A variação do custo incremental de vendas decorre da variação anterior uma vez que essas despesas estão diretamente ligadas ao valor faturado.

A variação do custo incremental de fabricação reflete a eficiência da área industrial, compreendendo o rendimento dos materiais e aproveitamento do equipamento e pessoal, sendo, portanto, de responsabilidade do setor de produção. As oscilações no preço dos materiais, evidenciadas pela variação do preço de compra, devem ser discutidas com 0 encarregado de suprimentos.

Vê-se, portanto, que as anormalidades são levantadas e localizadas com presteza e segurança. Esta maior atenção dada aos pontos críticos caracteriza a administração por exceção que, assim, poupa à diretoria a perda do tempo que representaria a leitura de dados que, estando dentro dos planos estabelecidos, não exigem decisóes complementares. Cumpre notar que essas evidências e justificativas se processam automática e rotineiramente, não havendo, portanto, necessidade de pesquisas demoradas e históricas.

O restante da demonstração apresenta elementos semelhantes aos já enunciados, agora classificados por linha de produto e cuja compreensão não oferece dificuldades.

Em complemento a essa demonstração, outras são apresentadas, onde cada elemento da primeira é devidamente analisado segundo o grau de detalhe requerido pela administração da emprêsa. Complementarmente, o setor responsável por essas apresentaçōes deve fazer sua crítica e fornecê-la por escrito e resumidamente à diretoria, de modo a adiantar à administração os primeiros esclarecimentos que, forçosamente, seriam solicitados.

\section{DEMONSTRAÇÃo DA SITUAÇÃO PATRIMONIAL}

A situação patrimonial é tratada com o mesmo cuidado dispensado aos problemas de custo e de modo integrado com o resultado econômico. Assim, o valor do lucro que 
figura nessa demonstração, feita mensalmente, é o mesmo que consta nas demonstrações econômicas. Também os estoques são apresentados pelos seus valôres padrões e, portanto, dentro dos mesmos critérios seguidos para as informações de natureza econômica. Destarte, tem-se, claramente, conhecimento das alterações ocorridas nos principais componentes do patrimônio da emprêsa e, também, do fluxo de fundos do período.

Os índices econômico-financeiros mais significativos para a emprêsa são apresentados em destaque, permitindo à diretoria uma visão nítida e completa da situação da emprêsa e de como ela está evoluindo.

9. SEGURANÇA NAS INFORMAÇõES

Tôda a manipulação de valôres prevista na Contabilidade Decisorial tem um contrôle contábil, embora feito extracontàbilmente. Esta movimentação de valôres segue um plano de contas próprio, estabelecido em conexão $\mathrm{c}^{r \mathrm{~m}} \mathrm{o}$ plano de contas da contabilidade geral, com o qual tem perfeito entrosamento. Assim sendo, tôdas as informações fornecidas pela CD estão de acôrdo com os dados contabilizados, oferecendo, portanto, a segurança necessária para a tomada de decisões importantes.

10. INFORMAÇõES PARA ESTUDOS ESPECIAIS

Para atender às necessidades de informações requeridas pelas diversas funções e níveis hierárquicos dentro da emprêsa, dados semelhantes precisam ser manipulados de várias maneiras. Em vista disto, os dados elementares são grupados em elementos modulados (building blockss), assim definidos por ROBERT BAYER: "Um elemento modulado é a menor unidade de dado que é requerida para satisfazer uma necessidade de informação e cuja obtenção é viável econômicamente".

Ésses elementos podem ser montados de diversas formas, de modo a se ter a informação final adaptada ao fim a que se destina. Assim, tanto são feitas as demonstrações rotineiras de resultado, como também, aquelas para estudos especiais, como, por exemplo: 
- para se saber se uma peça deve ser fabricada na emprêsa ou comprada pronta;

- para comparação de custos de processos de fabricação;

- para estudos sôbre vantagens de novos investimentos; ou

- para fixação de preços de venda em relação à concorrência, e outros mais.

Também, as informações necessárias aos escalóes inferiores da administração são preparadas, adequadamente, recorrendo-se aos building blocks.

\section{SIMPLICIDADE NA OPERAÇÃO}

A objetividade e a qualidade das informações fornecidas pela CD não trazem maior complexidade aos trabalhos de cálculo e preparação dos demonstrativos, como se poderia imaginar por um exame superficial do problema. Antes, ela traz maior simplicidade e rapidez na manipulação dos dados, o que reforça as vantagens do sistema. Além de se ter a informação certa no local certo, ela é fornecida no tempo certo.

A comparação do esfôrço requerido na $\mathrm{CD}$, com os trabalhos necessários quando se utiliza o custo por absorção, ilustra o que acabamos de dizer. Num sistema de custo histórico por absorção, os trabalhos no setor encarregado são executados seqüencialmente: primeiro, são dadas as entradas nos estoques e calculados os novos preços médios; depois, são dadas as saídas a débito das ordens de produção.

As despesas fornecidas pela contabilidade - após esta haver levantado seu balancete - são rateadas pelas seções, sendo os gastos das seções auxiliares a seguir apropriados às seções produtivas para, após o cálculo da taxa de cada seção, serem feitos os débitos às ordens de produção. Em seguida, feitos os cálculos das ordens de produção, custeiam-se as peças e produtos semi-acabados que são, então, registrados nas ordens de montagem e/ou aca- 
bamento. Sòmente após a va'orização destas últimas e de seu lançamento no estoque de acabados é que se pode ter - preço médio dos produtos para cálculo do custo dos produtos vendidos e, então, proceder-se à apuração do resultado. Percebe-se que qualquer atraso ou engano nos dados iniciais reflete-se em todo o processo.

Opostamente à longa seqüência linear acima descrita, na $\mathrm{CD}$, a partir de uma relação das quantidades vendidas no mês, por produto, pode-se, imediatamente, calcular a contribuição marginal padrão (ver modêlo da demonstração do resultado) e, ainda, com o dado de faturamento real, a variação do preço de venda. Durante o mês, e, portanto, antecipadamente, à medida que chegam os materiais na emprêsa, podem-se, imediatamente, calcular as variações do preço de comora. No fim do mês, a totalização das variações diárias fornece o dado a figurar na demonstração.

As variações do custo de fabricação são também apuradas, no decorrer do periodo, à medida em que se encerram as ordens de produção. Desta forma, ao se encerrar o mês, sòmente ficam faltando os dados da contabilidade referentes às despesas regulares e programadas, para que se possa montar a demonstração do resultado.

Vê-se, portanto, que os diversos elementos que formam o resultado são calculados independentemente. Além da diminuição do prazo para sua apresentação que o sistema oferece, qualquer engano cometido não invalida todo o trabalho, que pode ser corrigido sem dificuldades.

$O$ fato de serem utilizados preços e custos padrões elimina ainda a necessidade de se calcular preço médio para os estoques, o que traz uma redução bastante sensível no trabalho de seu contrôle: As fichas correspondentes são movimentadas apenas em quantidade. Sòmente os saldos finais são valorizados - pelos respectivos padrões - para figurarem nas demonstrações de situação patrimonial. 


\section{PRINCIPAIS VANTAGENS}

Resumindo as principais vantagens auferidas pela utilização da $\mathrm{CD}$, em seu primeiro estágio, é de interêsse mencionar:

- maior riqueza de informações, clareza e objetividade nas demonstrações de resultado;

- menor quantidade de dados para serem examinados pela administração superior;

- nítida segregação das causas que afetam o resultado, tais como volume de vendas, preços de venda e de compra, eficiência da fabricação, etc.;

- melhor visão das ocorrências anormais, através do destaque dado às variações em relação aos standards;

- maior rapidez na apresentação dos resultados;

- melhor conhecimento da rentabilidade da emprêsa, das linhas, das filiais e dos produtos;

- melhor definição da responsabilidade pelos gastos da emprêsa e pelas variações em relação aos standards;

- maior facilidade na elaboração de estudos especiais;

- maior segurança na política de preços e de vendas, baseada mais no que devem render os produtos do que em seus custos;

- segurança quanto aos dados fornecidos, pelo entrosamento com a contabilidade geral;

- possibilidade da implantação de serviços do tipo da demonstração da evolução patrimonial, do contrôle orçamentário e outros, empregados pela $C D$ em seu segundo estágio, em que se faz o planejamento do lucro;

- perfeita integração das informações, mais sensível, ainda, no segundo estágio;

- melhor acompanhamento da evolução da estrutura patrimonial da emprêsa, principalmente do capital de giro;

- melhor conhecimento das taxas de retôrno do capital empregado; 
- segurança nos estudos sôbre a lucratividade dos investimentos a serem feitos;

- e, como conseqüência, maiores objetividade e segurança na tomada de decisões.

\section{PLANEJAMENTO GERAL E PREVISÃo DO LUCRO}

$O$ que foi dito acima corresponde apenas a um primeiro estágio da Contabilidade Decisorial, que, pelas vantagens oferecidas, justifica ampla e seguramente sua adoção.

Com a implantação das técnicas previstas nesse estágio, e a consequiente elaboração das estatísticas dos dados então apurados, a emprêsa passa a estar em condições de aplicar os demais conceitos previstos pela $\mathrm{CD}$.

Em sua mais completa forma a $C D$ prevê a elaboração de um planejamento geral para a emprêsa em seu todo, incluindo o planejamento do lucro, contrôle orçamentário entrosado com os programas de venda e produção, estudo de novos investimentos, determinação de rentabilidade do capital e análises semelhantes, de cujas vantagens citaríamos, a título de exemplo, apenas três:

- condições para um desenvolvimento planejado;

- antevisão dos períodos críticos para a situação econômica e/ou financeira;

- investimento em projetos mais lucrativos.

Nesse estágio, os contrôles tornar-se-ão ainda mais simples, pois basta que se analisem os desvios anormais em relação ao plano, ocorridos no período, para que se tomem as medidas corretivas necessárias.

\section{VERSATILIDADE - CUIDADOS NA IMPLANTAÇÃO}

A CD oferece, ainda, uma grande versatilidade quanto à sua aplicação, podendo ser introduzida, pràticamente, em qualquer emprêsa. Em vista disto, de acôrdo com as peculiaridades da emprêsa, com o nível de formação do pessoal e com o interêsse da diretoria, a $C D$ reveste-se de características próprias a cada lugar onde é aplicada. Por esta razão, e em virtude de suas inovações de caráter con- 
ceitual e, principalmente, da integração que promove os contrôles administrativos, é recomendável que os estudos para a introdução da Contabilidade Decisorial na emprêsa sejam feitos por pessoal experimentado nesse sistema, pois a má orientação nas adaptações ou a improvisação nas soluções podem prejudicar bastante o valor das informações fornecidas e, conseqüentemente, a tomada das decisões mais acertadas.

Êsse é o caminho mais seguro e mais rápido - e, consequientemente, mais econômico — para dotar a emprêsa de técnicas administrativas avançadas que, na mão de dirigentes hábeis, concorrerão, decisivamente, para a melhoria da eficiência geral e maior progresso da organização.

\section{BIBLIOGRAFIA}

Werolin, A. E. A Elaboração de Um Orçamento Variável, Revista de Administração de Emprêsas, Rio de Janeiro, Fundação Getúlio Vargas, vol. 5, n. ${ }^{\circ} 16$, setembro de 1965.

DiAs, Ivan Pinto. Algumas Observações sôbre a Margem de Contribuição, Revista de Administração de Emprêsas, Rio de Janeiro: Fundação Getúlio Vargas, vol. 7, n. ${ }^{\circ}$ 24, setembro de 1967.

BAyer, Robert. Profitability Accounting for Planning and Control, Nova Iorque, The Ronald Press Company, 1963.

Schoeps, Wolfgang. O Método de Custeio Direto, Revista de Administração de Emprêsas, Rio de Janeiro: Fundação Getúlio Vargas, vol. 1, n. ${ }^{\circ}$, setembro/dezembro de 1961 . 